\title{
Advances in tracheal reconstruction and tissue engineering
}

\author{
Al Haitham Al Shetawi ${ }^{1}$, Joanna Weber ${ }^{1,2}$, Mirza Zain Baig ${ }^{1,2}$, Zaid Muslim ${ }^{2,3}$, Faiz Bhora ${ }^{1,2,3}$ \\ 'Division of Surgical Oncology, Department of Surgery, Nuvance Health, Poughkeepsie, NY 12601, USA. \\ ${ }^{2}$ Rudy L. Ruggles Biomedical Institute, Nuvance Health, Danbury, CT 06810, USA. \\ ${ }^{3}$ Division of Thoracic Surgery, Department of Surgery, Nuvance Health, Danbury, CT 06810, USA.
}

\begin{abstract}
Correspondence to: Dr. Al Haitham Al Shetawi, Division of Surgical Oncology, Department of Surgery, Nuvance Health, 45 Reade Place, Poughkeepsie, NY 12601, USA. E-mail: al-haitham.al-shetawi@nuvancehealth.org; Dr. Faiz Bhora, Division of Surgical Oncology, Department of Surgery, Nuvance Health, 45 Reade Place, Poughkeepsie, NY 12601, USA.

E-mail: faiz.bhora@nuvancehealth.org
\end{abstract}

How to cite this article: Al Shetawi AH, Weber J, Baig MZ, Muslim Z, Bhora F. Advances in tracheal reconstruction and tissue engineering. Plast Aesthet Res 2021;8:38. https://dx.doi.org/10.20517/2347-9264.2021.09

Received: 22 Jan 2021 First Decision: 17 May 2021 Revised: 18 Jun 2021 Accepted: 1 Jul 2021 First online: 9 Jul 2021

Academic Editor: Matthew Spector Copy Editor: Xi-Jun Chen Production Editor: Xi-Jun Chen

\begin{abstract}
Tracheal stenosis represents a significant challenge. Surgeons continue to search for appropriate reconstructive techniques and grafting materials for long tracheal segment reconstruction. Grafts can be classified as synthetic, allogenic, autogenic, transplant, and engineered. Although none of these grafts have provided overwhelming success, acellular composite engineered grafts have shown early promise and can be applied in benign and malignant tracheal diseases. Intraluminal granulation tissue causing re-stenosis is the biggest challenge in tracheal reconstruction. Tracheal wound healing and tissue regeneration pathways must be deeply explored and better characterized to advance the field of tracheal reconstruction.
\end{abstract}

Keywords: Tracheal reconstruction, tracheoplasty, tissue engineering

\section{INTRODUCTION}

Airway stenosis is associated with significant morbidity and mortality. Stenosis may be the result of prolonged intubation, injury due to tracheostomy, autoimmune conditions, cancer, infections, or trauma ${ }^{[1]}$ [Figure 1]. Postintubation injury is the most common cause of tracheal stenosis, with an estimated 


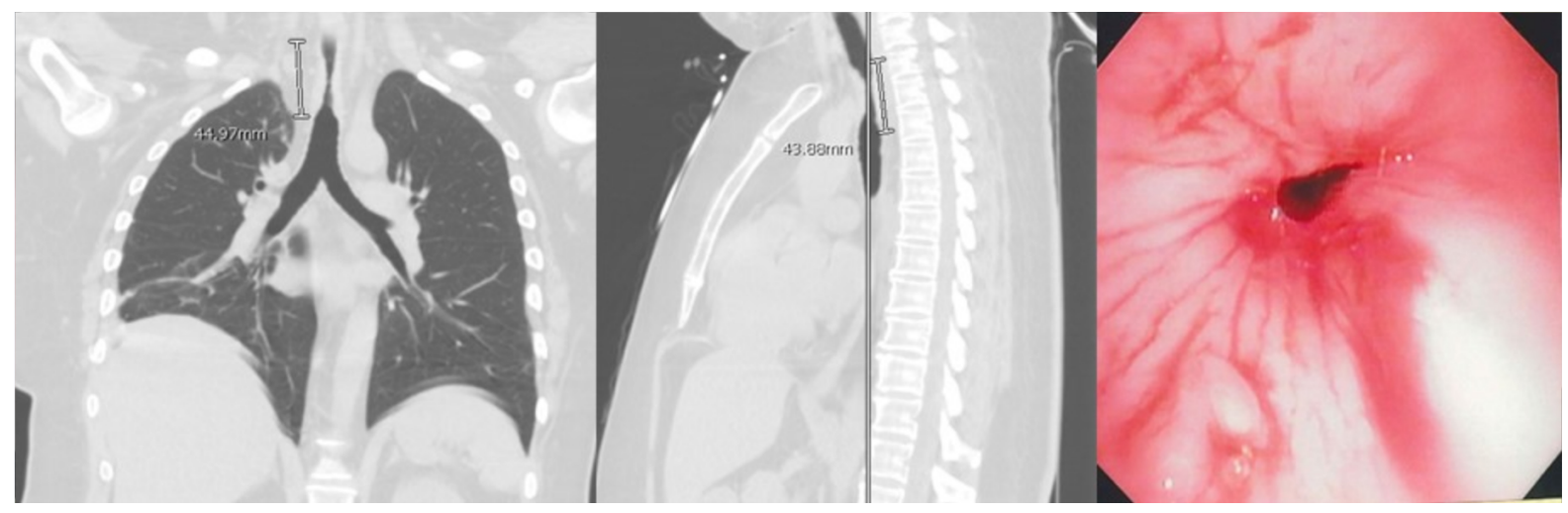

Figure 1. CT scan and bronchoscopic images of post-intubation tracheal stenosis. The development of intraluminal granulation tissue causes significant narrowing of the airway.

incidence of 4.9 cases per million per year ${ }^{[2]}$, and in some reports, an incidence as high as $19 \%$ and $65 \%$ in tracheal intubation and tracheostomy patients, respectively ${ }^{[3,4]}$. While short segments $(<2 \mathrm{~cm})$ of postintubation stenosis can be treated with conservative techniques, including endoluminal ablation and dilation, in the United States, about 4000 cases per year of postintubation stenosis are treated by resection and reconstruction ${ }^{[5-7]}$. Comparatively rarer causes of tracheal stenosis are acute trauma or cancer; however, these causes often necessitate a surgical approach for definitive treatment. For example, primary tracheal cancers have an approximate prevalence of 2.6 cases per million people per year ${ }^{[8-10]}$. While about $23 \%$ of these patients are treated with surgery, those who undergo surgery have the best outcomes in terms of overall survival ${ }^{[8]}$.

Tracheal resection and reconstruction via end-to-end anastomosis have been traditionally used to manage severe tracheal stenosis ${ }^{[11]}$. However, this approach is limited to resecting less than half of the length of the adult trachea or $\leq 4-6 \mathrm{~cm}$ to limit tension on the anastomosis ${ }^{[12]}$. Several techniques have been used to minimize tension on the suture line. These include laryngeal, suprahyoid, hilar, and pericardial release maneuvers ${ }^{[12,13]}$. Extensive mobilization by circumferential dissection risks devascularization of the anastomosis, anastomotic dehiscence, or restenosis and should be avoided ${ }^{[7]}$. For the patient with recurrent stenosis after primary reconstruction, slide tracheoplasty represents a possible treatment option. The procedure involves dividing the trachea at the midpoint of the stenosis before longitudinally dividing and spatulating the proximal and distal ends. The resulting anastomosis between the two tracheal segments is able to achieve a sufficiently larger lumen size ${ }^{[14]}$. Some studies have reported high success rates with this technique in patients with a history of prior reconstruction ${ }^{[15]}$. Primary reconstruction of the trachea with direct anastomosis remains the gold standard ${ }^{[12]}$. However, when the affected length of the trachea exceeds the anatomical limitations for primary reconstruction, the use of an additional grafting material might be necessary ${ }^{[16]}$ [Figure 2]. Grafts must be laterally rigid to provide structural integrity and strength to the airway while being longitudinally flexible in order to offer adequate compliance to accommodate neck movements ${ }^{[11]}$.

\section{GRAFTING METHODS IN TRACHEAL RECONSTRUCTION Synthetic materials}

Numerous synthetic materials have been tested in experimental animal research, and it has become evident that definitive synthetic prosthetic replacement for the airway is not feasible ${ }^{[17]}$. They are non-biocompatible and result in granulation tissue formation, infection, dehiscence, and erosion into surrounding structures leading to fistula formation ${ }^{[18,19]}$. A silicone rubber tube with a non-terminal Dacron ring is the primary 

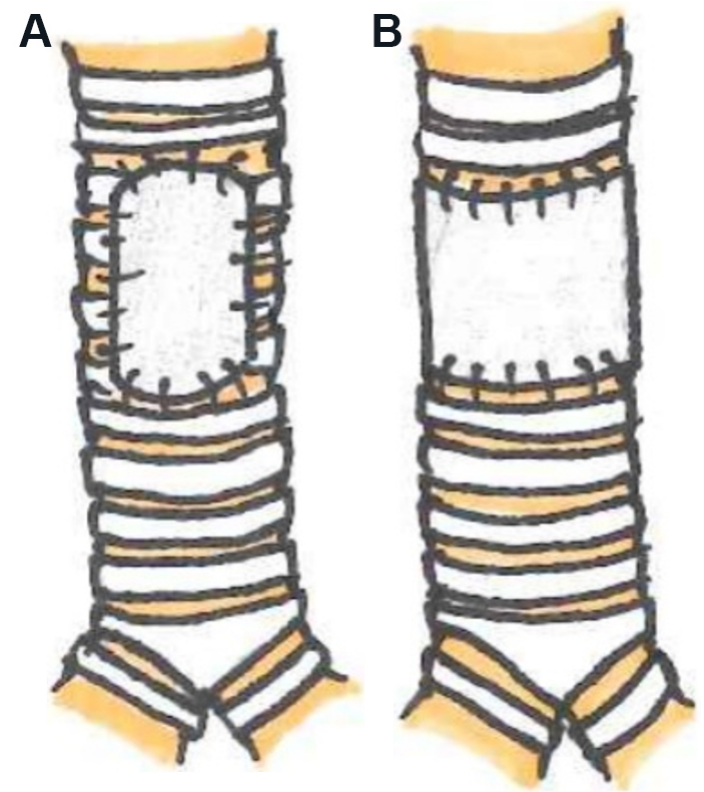

Figure 2. Partial (A) or circumferential (B) grafts may be used to reconstruct a significant length of diseased trachea.

design of solid prostheses. Neville et al. ${ }^{[20]}$, placed these prostheses in 35 patients and observed high morbidity. Ten (29\%) patients developed suture line granulomas, and one patient had dehiscence. In another study, solid prostheses were used in nine patients ${ }^{[21]}$. Eight patients died from prostheses-related complications. Only one patient was alive at a 13-month follow-up. Hence solid prostheses are not a viable long-term option due to high morbidity and mortality.

Porous prostheses are more biocompatible than solid prostheses as they allow connective tissue ingrowth, epithelial migration, and incorporation into native tracheal tissue ${ }^{[18]}$. Schultz introduced a porous titanium prosthesis that showed early success in rats by demonstrating epithelialization and integration ${ }^{[22]}$. Clinical use in a 56-year-old man who underwent a laryngectomy also demonstrated promising results ${ }^{[23]}$. At 16 months follow-up, he was able to expectorate and breathe. However, this technique is only limited to the proximal part of the trachea and cannot be utilized for extended tracheal reconstructions. Other investigators have reported significant complications and setbacks with porous prosthetics due to extensive proliferation of scar tissue leading to obstruction. In addition, large segments of the prosthesis remain uncovered with epithelium leading to bacterial colonization and infection ${ }^{[18]}$.

\section{Autologous tissue}

Numerous autologous tissues have been used to repair tracheal defects. They have the distinct advantage of not inciting an immunogenic response and hence have no risk for acute or chronic rejection ${ }^{[24}$. Previous experiences with autologous tubular conduits constructed from the esophagus, skin, small bowel, or aorta have generally been limited due to obstruction as they were unable to tolerate the normal pressure variations of the respiratory system ${ }^{[25]}$. Ren et al. ${ }^{[26]}$, reported a case where they used an extended bronchial flap to repair a long segment tracheal defect in a 48-year-old man with adenoid cystic carcinoma. At 17 months follow-up, the authors only reported mild stenosis and no tumor relapse. However, there has been debate whether it is beneficial to sacrifice the right upper lobe to counterbalance the radical resection of malignant tumors, as seen in this case ${ }^{[27]}$. 
The largest clinical experience utilizing an autologous tissue composite for tracheal repair was reported by Fabre et al. ${ }^{[24]}$. The authors used a free forearm fasciocutaneous flap reinforced by rib cartilage interposed transversally in the subcutaneous tissue to construct a tube. The flap was anastomosed to the internal mammary vessels. Sixteen patients were treated with this flap. All patients were successfully extubated on postoperative day 1 . The 5 -year survival rate was $64.8 \%$. No airway collapse was detected upon repeated endoscopies, dynamic computed tomography scans, or spirometry. Two patients who had reported dysphagia preoperatively were able to resume oral feeding. The main limitations for this newly constructed trachea were the lack of mucociliary clearing and the risk of cartilage fracture in elderly patients ${ }^{[19]}$. Several case reports using variations on this reinforced free-flap method with a variety of supporting structures have also been successful in reconstructing large $(>5 \mathrm{~cm})$ and irregularly shaped tracheal $\operatorname{defects}^{[28-31]}$. Patients reportedly were doing well at the final follow-up, maintaining a functional airway.

\section{Allografts}

Decellularized allografts are biocompatible. They are non-immunogenic and therefore do not require immunosuppression or growth factor supplementation. This makes them good for patients with the oncologic disease. They do, however, lack good vascularization, which is often responsible for their degeneration. These grafts also lack lateral rigidity and therefore require stent placements ${ }^{[19]}$. Stenting may predispose these patients to inflammation, granulation, infection, and erosion into surrounding structures $^{[32]}$.

Azorin et al. ${ }^{[33]}$, reported the first aortic allograft for tracheal replacement in 2006. They used a fresh autologous abdominal aorta allograft to replace the trachea in a 68-year-old patient with squamous cell carcinoma. A silicone Dumon stent was introduced as well. The patient died six months after surgery from pneumonia and septic shock. Another study reported using cryopreserved thoracic aorta allografts from cadaveric donors in six patients with malignant airway disease $\mathrm{e}^{[34]}$. In order to promote revascularization, the allograft was wrapped in a pectoralis major muscle flap and pedicled to its thoraco-acromial blood supply. At the time of publication, four patients were alive and disease-free, with a mean follow-up of 34 months (range 26-42 months). Complications observed included tracheoesophageal fistula, anterior spinal cord ischemia, stent migration, and fatal hemoptysis. The autopsy revealed the absence of cartilage regeneration and respiratory epithelium and the presence of inflammatory infiltrates in the allografts. The authors also observed significant shortening of the grafts.

Similar reports for tracheal allografts have also been reported in the literature. Jacobs et al. ${ }^{[35]}$, published the first study where they treated 24 children with congenital, post-traumatic, and post-intubation stenosis with tracheal allografts acquired from 16-64-year-old cadaveric donors. All grafts were chemically treated to kill all cells and remove all major histocompatibility markers. The lateral walls of the narrowed portion of the native tracheal segment were removed and the graft inserted. A silicone stent was used to provide graft support for up to 10-12 weeks. The follow-up period ranged from 5 months to 10 years. Twenty patients (83\%) were alive at the time of publication of this report. Epithelialization in the tracheal lumen was observed in sixteen patients. Native ciliary respiratory epithelium colonization occurred at the graft ends but not in the midportion of the graft. None of the patients underwent rejection or required immunosuppression.

In another study, the same technique was utilized in six patients presenting with congenital, post-traumatic, and post-intubation stenosis ${ }^{[36]}$. One patient died on postoperative day 12 due to a fistula formation to the innominate artery. Of the remaining five survivors, those who had their stents removed required re-stenting due to tracheomalacia. One patient was able to have their stent removed permanently and underwent 
frequent bronchoscopy for granulation tissue removal. One patient underwent stenting with a tracheostomy tube and was decannulated during follow-up. The final patient still had a tracheostomy and stent placed at their most recent follow-up. Dramatic improvements in pulmonary function tests were reported.

Propst et al. ${ }^{[37]}$, utilized this technique in ten children and reported a high rate of re-interventions with an average of 7.38 procedures per patient. Re-interventions included tracheal dilation, granulation removal, laser ablation, mitomycin application, stent placement, supraglottoplasty, arytenoidectomy, tonsillectomy, adenoidectomy, laryngotracheoplasty, and slide tracheoplasty.

Tracheal allografts are complicated by a high morbidity rate. Therefore, their role is currently unclear. It is reasonable to defer to non-surgical treatments before resorting to allografts. This technique is only limited to benign conditions as the membranous posterior wall of the native trachea is left intact. The need for longterm stenting, the development of malacia, and limited epithelialization are other factors that limit the use of tracheal allografts.

\section{Tracheal transplantation}

Tracheal transplantation is currently limited by the need for immunosuppression and the difficulty in establishing adequate vascularization ${ }^{[19]}$. Initial attempts at transplantation began with a one-stage approach, combining the donor trachea with a blood supply by omentopexy to provide early revascularization ${ }^{[38,39]}$. Although no long-term clinical outcomes were reported in a 1979 study, in 1993, Levashov et al. ${ }^{[38]}$ reported early rejection at 10 days post-transplantation despite immunosuppressive therapy and progressive stenosis treated 4 months later with a permanent silicone stent. Delaere et al ${ }^{[17]}$, developed a two-stage technique in which they placed the donor trachea in the recipient's forearm ${ }^{[40]}$. This allowed revascularization to occur, maintaining the viability of the graft. Buccal mucosa of the recipient was used to replace the posterior tracheal wall. Immunosuppression was maintained using tacrolimus, azathioprine, and corticosteroids. The trachea was then transplanted into its orthotopic position. The first patient to undergo this procedure was a 55 -year-old woman with a chronic history of post-traumatic tracheal obstruction treated with stents and complicated by chronic infections, granulation, and halitosis. Post-procedure she had no more episodes of pneumonia or bronchitis, and her pulmonary function tests improved remarkably. A similar two-stage technique using omentum for revascularization has also been attempted by Xu et al.$^{[4]]}$ in a 3-patient case series. A $6 \mathrm{~cm}$ segment of donor trachea was implanted in the greater omentum of each recipient in stage 1 . In stage 2, 3-5 weeks later, the tracheal allograft and omental pedicle were transplanted to the orthotopic position, replacing a comparable length of excised diseased trachea. All patients received long-term immunosuppressive therapy, including tacrolimus, mycophenolate mofetil, and methylprednisolone. No major complications or symptoms of bronchiolitis obliterans were observed, and postoperative bronchoscopy showed a well-healed tracheal anastomosis. Early experience with these two-stage techniques has therefore been promising. They are, however, limited by the need for long-term immunosuppression and the lack of circumferential vascularization.

\section{TISSUE ENGINEERED GRAFTS}

Although attempts to reconstruct the trachea with allografts and autografts are still being explored, the lack of overwhelming success of these methods and the difficulties encountered with tracheal transplantation, both technically and logistically, has caused tissue engineering to be explored as the next possible solution. The ideal engineered trachea graft design must closely mimic the healthy native trachea. In terms of mechanical function, the graft should be longitudinally flexible but still provide lateral rigidity for airway patency. Furthermore, the graft must be able to retain these mechanical properties to remain functional. Thus the grafts must either be non-degradable or predictably degradable and replaced with the patient's 
own tissue on a matching timeline. In addition to mechanical requirements is the functional role of the trachea. The healthy native trachea is lined with specialized airway epithelium composed of secretory and ciliated cells. This specialized tissue protects the lower airways from inhaled contaminants by trapping the debris in mucous and propelling it up and out. An engineered tracheal graft would ideally also be able to replicate this feature. As with many other engineered tissues, avoiding immunogenicity is also a goal of engineered tracheal grafts. This may be accomplished either with an acellular graft or with patient-derived cells.

Unfortunately, the initial clinical application of tissue engineered tracheas demonstrated poor results causing tracheal tissue engineering to be met with skepticism. These experiments, conducted by Paolo Maccharini, were an overzealous clinical application of untested decellularized tracheas. Further investigations into these experiments resulted in convictions of medical malpractice and academic misconduct due to the misrepresentation of successful results, fake data, and obfuscation of negative outcomes ${ }^{[42,43]}$. This has caused many other researchers in the field to proceed with an abundance of caution, slowing the progress of engineered tracheas to clinical practice, although probably to the benefit of the field. With the wide variety of approaches to engineered tracheal grafts as well as the innate complexities associated with tracheal operations, thorough pre-clinical assessments must be done to ensure patient safety.

Cells, scaffolds, and growth-stimulating signals are considered to be the three key components required for successfully creating an engineered tissue ${ }^{[44,45]}$. Cell sourcing is often a limiting factor in tissue engineering due to the number of cells needed for the grafts and the preparation time required to collect, process, and apply the cells to the graft. For patient-derived cells in engineered tracheal grafts, cells could be sourced from donor cartilage sites or mesenchymal stem cells to provide cells for the mesenchyme, while airway epithelial cells would be harvested from the bronchi ${ }^{[46-48]}$. If these cells need to be expanded prior to use, this can add weeks of lead time to the production of the graft and limiting their use to non-emergent cases. One work-around for the cell-associated problems is to rely on post-implantation colonization of the graft by the recipient's own cells, allowing a graft to use patient-derived cells without the need for a pre-implantation cell culture period.

Scaffolds provide an attachment point for the cells, holding them in place in the graft. These scaffolds can consist of isolated matrix components such as collagen or a complex, mature, cell-elaborated matrix obtained by decellularization ${ }^{[9-54]}$. Efficient decellularization removes cells, cell components, and nuclear and membrane fragments from a source tissue leaving only the extracellular matrix, greatly reducing potential immunogenic reactions or apoptotic responses ${ }^{[55-57]}$. Without treatment with artificial cross-linking agents, native binding sites remain intact, theoretically increasing the potential for interaction with the recipient's cells and providing a cell niche that directs the differentiation of the cells towards the desired cell type ${ }^{[50]}$. Synthetic scaffolds can also be used. These scaffolds can be tailored during manufacturing to produce the desired thickness and strength, and surface treatments can enhance cell attachment; however, immunogenic reactions either to the materials themselves or their degradative products remain a concern $^{[58-60]}$. Some engineered tracheal grafts entirely skip the use of a scaffold instead of relying on their chosen cells to build a new matrix from scratch. This is most often seen with cartilage-only grafts but involves extensive additional time for production ${ }^{[1,62]}$.

Growth-stimulating signals such as growth factors are commonly used to accelerate the in vitro growth of engineered tracheal grafts and strengthen the tissue ${ }^{[59,62,63]}$. The use of decellularized scaffolds can also provide growth-stimulating signals both through cell niches as well as with matrix-bound growth factors 

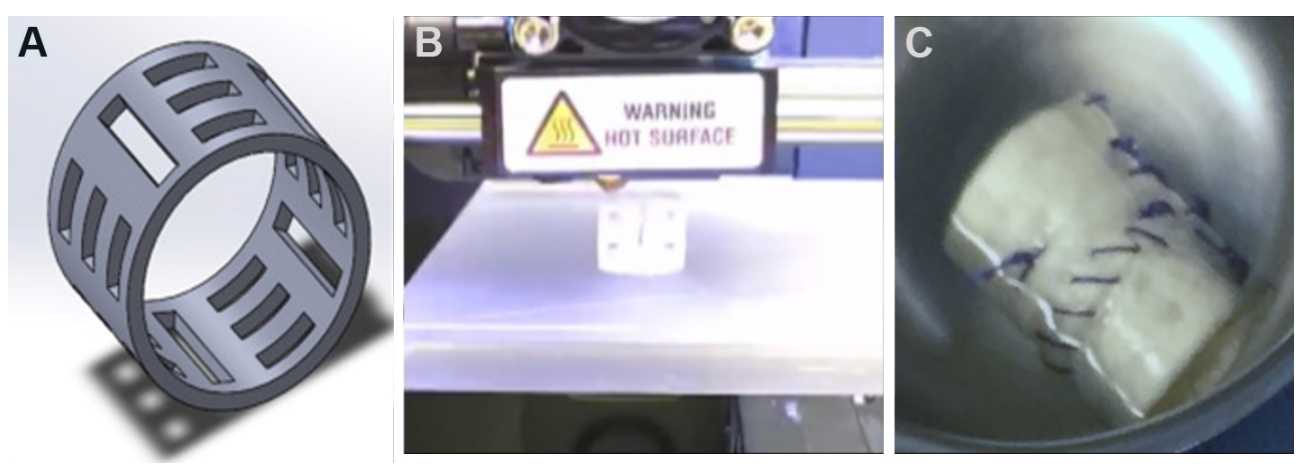

Figure 3. 3D printing can allow for easy customization of engineered tracheal grafts using computer-assisted modeling (A). The use of biocompatible materials and benchtop 3D printers (B) can allow for the rapid creation of patient-specific composite grafts (C).

that are retained through the decellularization process. Some of the same growth factors used in vitro can be supplemented in vivo to accelerate the post-implantation incorporation of the grafts with the surrounding tissue. Angiogenic growth factors may also be supplemented to promote vascularization of the graft. Vascularization of the implanted graft is necessary to provide the embedded cells with oxygen, nutrients, and waste removal.

Vascularization can also be accomplished by pre-implantation of the graft in a highly vascular area of the body to produce a pedicled graft that is later transposed to its orthotopic location ${ }^{[64,65]}$. This prevascularization period, however, adds additional time to the development of the tracheal graft, again precluding it from emergency use. In addition, the use of exogenous growth factors post-implantation would also be contraindicated in patients needing tracheal reconstruction due to malignancy.

To prevent the inward collapse of the tracheal grafts, composite grafts rely on the addition of a secondary rigid support structure, usually in a synthetic material, that serves to mimic the function of the native tracheal cartilage rings, providing needed lateral rigidity. These rigid support structures can either be derived from off-the-shelf stents, cast in custom-fabricated molds, or be rapidly prototyped and customized to patient-specific dimensions with the use of biocompatible 3D-printed plastic polymers ${ }^{[1-53,65]}$ [Figure 3].

The largest series of pre-clinical trials in a large animal model tested composite engineered constructs composed of decellularized surgical grafting patches supported by a $3 \mathrm{D}$-printed biocompatible structure $^{[52-54]}$. These acellular composite constructs are particularly attractive since they circumvent immunological issues and have the added benefit of being implantable without an immediate blood supply that would be required to support embedded cells. In these grafts, the decellularized surgical patch materials served as the cell scaffold, theoretically providing the necessary physiochemical cues and cell niches needed to attract and sustain a healthy cell population ${ }^{[57]}$. An additional advantage to using decellularized materials is the strength that is innate to the material due to the complex composition and naturally cross-linked collagen network of a cell-remodeled mature matrix, providing an air-tight barrier that can immediately withstand intrathoracic pressure variances during breathing. In these composite grafts, the embedded rigid support structure prevented graft malacia and avoided the need for intraluminal stenting, which can further damage the native trachea and prevent epithelial migration onto the graft surface. Animals in these studies that underwent anterior reconstruction had the longest survival times, demonstrating that these grafts were able to meet the functional and mechanical requirements of the trachea. Without the use of exogenous growth factors, the need for immunosuppression, or additional stenting procedures, acellular composite grafts such as these hold the most promise for wide applicability to tracheal reconstructive needs be it due to 

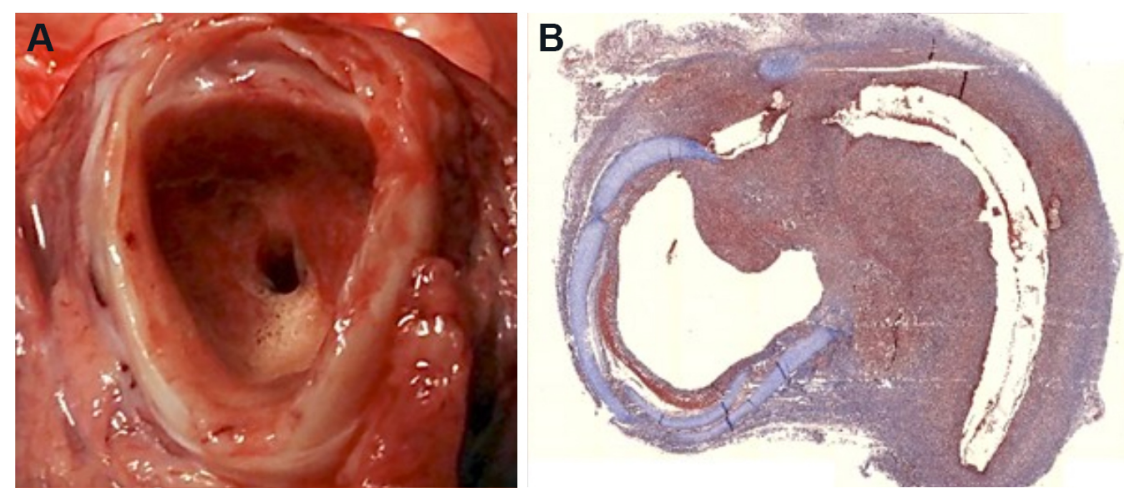

Figure 4. Gross (A) and histologic (B, stained with Masson's Trichrome) views of engineered graft-induced tracheal granulation tissue in the preclinical pig model.

trauma, congenital malformation, or malignancy while relieving any additional burden of using self- or donor-derived tissues or cells.

Although preclinical assessments of many different designs of engineered tracheal grafts have demonstrated the feasibility of creating mechanically suitable grafts, implantation into recipient animals has shown that problems with tissue integration and healing still exist ${ }^{[51-54,61,63,66-68]}$. Most notably, significant obstructing stenosis, due to the development of either peri-anastomotic granulation tissue or mid-graft fibrosis, remains a persistent problem and a final common pathway for the failure of many types of tracheal grafts [Figure 4]. Thus, to overcome these failures, our understanding of tracheal wound healing will need to be significantly more advanced, and specific research into mechanisms of graft-induced inflammation and wound healing will be necessary.

\section{CONCLUSION}

The search for an appropriate grafting material and method for extensive tracheal reconstruction remains a challenge. Although a rather extensive and diverse set of approaches have been made to this effect, including transplantation, synthetic and natural grafts, and engineered grafts, none have been proven to address all concerns and provide the ideal tracheal replacement adequately. However, tracheal reconstruction will benefit from the accumulation of knowledge from the continued advancements in tracheal transplantation, wound healing, and tissue engineering.

\section{DECLARATIONS}

\section{Authors' contributions}

Conception and design: Al Shetawi AH, Weber J, Bhora F

Drafting of the article: Al Shetawi AH, Weber J, Baig MZ, Muslim Z

Critical revision of the article for important intellectual content: Al Shetawi AH, Weber J, Bhora F

Final approval of the article: Al Shetawi AH, Weber J, Baig MZ, Muslim Z, Bhora F

\section{Availability of data and materials}

Not applicable.

\section{Financial support and sponsorship}

None. 


\section{Conflicts of interest}

All authors declared that there are no conflicts of interest.

\section{Ethical approval and consent to participate}

Not applicable.

\section{Consent for publication}

Not applicable.

\section{Copyright}

(c) The Author(s) 2021.

\section{REFERENCES}

1. Gelbard A, Francis DO, Sandulache VC, Simmons JC, Donovan DT, Ongkasuwan J. Causes and consequences of adult laryngotracheal stenosis. Laryngoscope 2015;125:1137-43. DOI PubMed PMC

2. Ramalingam H, Sharma A, Pathak V, Narayanan B, Rathod DK. Delayed diagnosis of postintubation tracheal stenosis due to the coronavirus disease 2019 pandemic: a case report. A A Pract 2020;14:e01269. DOI PubMed PMC

3. Stauffer JL, Olson DE, Petty TL. Complications and consequences of endotracheal intubation and tracheotomy. Am J Med 1981;70:6576. DOI PubMed

4. Jamil A, Still S, Schwartz GS, Podgaetz E, Mason DP. Tracheal resection for tracheal stenosis. Proc (Bayl Univ Med Cent) 2020;33:15-8. DOI PubMed PMC

5. Bhora FY, Ayub A, Forleiter CM, et al. Treatment of benign tracheal stenosis using endoluminal spray cryotherapy. JAMA Otolaryngol Head Neck Surg 2016;142:1082-7. DOI PubMed

6. Nouraei SA, Ma E, Patel A, Howard DJ, Sandhu GS. Estimating the population incidence of adult post-intubation laryngotracheal stenosis. Clin Otolaryngol 2007;32:411-2. DOI PubMed

7. Prokakis C, Koletsis EN, Dedeilias P, Fligou F, Filos K, Dougenis D. Airway trauma: a review on epidemiology, mechanisms of injury, diagnosis and treatment. J Cardiothorac Surg 2014;9:117. DOI PubMed PMC

8. Baig MZ, Weber JF, Connery CP, Bhora FY. A SEER database cohort of 868 patients with primary tracheal cancers: characteristics and outcomes and the role of bronchoscopic interventions. IJS Oncology 2021;5:90. DOI

9. Urdaneta AI, Yu JB, Wilson LD. Population based cancer registry analysis of primary tracheal carcinoma. Am $J$ Clin Oncol 2011;34:32-7. DOI PubMed

10. Agrawal S, Jackson C, Celie KB, et al. Survival trends in patients with tracheal carcinoma from 1973 to 2011 . Am J Otolaryngol 2017;38:673-7. DOI PubMed

11. BELSEY R. Resection and reconstruction of the intrathoracic trachea. Br J Surg 1950;38:200-5. DOI PubMed

12. Kirschbaum A, Teymoortash A, Suárez C, et al. Treatment of large tracheal defects after resection: laryngotracheal release and tracheal replacement. Auris Nasus Larynx 2016;43:602-8. DOI PubMed PMC

13. Broussard B, Mathisen DJ. Tracheal release maneuvers. Ann Cardiothorac Surg 2018;7:293-8. DOI PubMed PMC

14. Tsang V, Murday A, Gillbe C, Goldstraw P. Slide tracheoplasty for congenital funnel-shaped tracheal stenosis. Ann Thorac Surg 1989;48:632-5. DOI PubMed

15. Sidell DR, Hart CK, Tabangin ME, et al. Revision thoracic slide tracheoplasty: outcomes following unsuccessful tracheal reconstruction. Laryngoscope 2018;128:2181-6. DOI PubMed

16. Redmann AJ, Rutter MJ, de Alarcon A, et al. Cervical slide tracheoplasty in adults with laryngotracheal stenosis. Laryngoscope 2019;129:818-22. DOI PubMed

17. Delaere P, Van Raemdonck D. Tracheal replacement. J Thorac Dis 2016;8:S186-96. DOI PubMed PMC

18. Doss AE, Dunn SS, Kucera KA, Clemson LA, Zwischenberger JB. Tracheal replacements: part 2. ASAIO J 2007;53:631-9. DOI PubMed

19. Etienne H, Fabre D, Gomez Caro A, et al. Tracheal replacement. Eur Respir J 2018;51:1702211. DOI PubMed

20. Neville WE, Bolanowski JP, Kotia GG. Clinical experience with the silicone tracheal prosthesis. J Thorac Cardiovasc Surg 1990;99:604-12; discussion 612-3. PubMed

21. Toomes H, Mickisch G, Vogt-Moykopf I. Experiences with prosthetic reconstruction of the trachea and bifurcation. Thorax 1985;40:32-7. DOI PubMed PMC

22. Schultz P, Vautier D, Chluba J, Marcellin L, Debry C. Survival analysis of rats implanted with porous titanium tracheal prosthesis. Ann Thorac Surg 2002;73:1747-51. DOI PubMed

23. Debry C, Dupret-Bories A, Vrana NE, Hemar P, Lavalle P, Schultz P. Laryngeal replacement with an artificial larynx after total laryngectomy: the possibility of restoring larynx functionality in the future. Head Neck 2014;36:1669-73. DOI PubMed

24. Fabre D, Kolb F, Fadel E, et al. Successful tracheal replacement in humans using autologous tissues: an 8-year experience. Ann Thorac Surg 2013;96:1146-55. DOI PubMed

25. Grillo HC. Tracheal replacement: a critical review. Ann Thorac Surg 2002;73:1995-2004. DOI PubMed 
26. Ren YJ, Zheng H, Shen LX, et al. A novel technique of long-segment tracheal repair with extended bronchial flap of right upper and main bronchus plus tracheoplasty. Ann Thorac Surg 2015;99:2188-90. DOI PubMed

27. Abouarab AA, Elsayed HH, Elkhayat H, Mostafa A, Cleveland DC, Nori AE. Current solutions for long-segment tracheal reconstruction. Ann Thorac Cardiovasc Surg 2017;23:66-75. DOI PubMed PMC

28. Fukunaga Y, Sakuraba M, Miyamoto S, et al. One-stage reconstruction of a tracheal defect with a free radial forearm flap and free costal cartilage grafts. J Plast Reconstr Aesthet Surg 2014;67:857-9. DOI PubMed

29. Teng MS, Malkin BD, Urken ML. Prefabricated composite free flaps for tracheal reconstruction: a new technique. Ann Otol Rhinol Laryngol 2005;114:822-6. DOI PubMed

30. Beldholm B, Wilson M, Gallagher R, Caminer D, King M, Glanville A. Reconstruction of the trachea with a tubed radial forearm free flap. J Thorac Cardiovasc Surg 2003;126:545-50. DOI PubMed

31. Yu P, Clayman GL, Walsh GL. Human tracheal reconstruction with a composite radial forearm free flap and prosthesis. Ann Thorac Surg 2006;81:714-6. DOI PubMed

32. Ko PJ, Liu CY, Wu YC, et al. Granulation formation following tracheal stenosis stenting: influence of stent position. Laryngoscope 2009;119:2331-6. DOI PubMed

33. Azorin JF, Bertin F, Martinod E, Laskar M. Tracheal replacement with an aortic autograft. Eur J Cardiothorac Surg 2006;29:261-3. DOI PubMed

34. Wurtz A, Porte H, Conti M, et al. Surgical technique and results of tracheal and carinal replacement with aortic allografts for salivary gland-type carcinoma. J Thorac Cardiovasc Surg 2010;140:387-93.e2. DOI PubMed

35. Jacobs JP, Quintessenza JA, Andrews T, et al. Tracheal allograft reconstruction: the total North American and worldwide pediatric experiences. Ann Thorac Surg 1999;68:1043-51. DOI PubMed

36. Jacobs JP, Elliott MJ, Haw MP, Bailey C, Herberhold C. Pediatric tracheal homograft reconstruction: a novel approach to complex tracheal stenoses in children. J Thorac Cardiovasc Surg 1996;112:1549-60. DOI PubMed

37. Propst EJ, Prager JD, Meinzen-Derr J, Clark SL, Cotton RT, Rutter MJ. Pediatric tracheal reconstruction using cadaveric homograft. Arch Otolaryngol Head Neck Surg 2011;137:583-90. DOI PubMed

38. Levashov Y, Yablonsky P, Cherny S, Orlov S, Shafirovsky B, Kuznetzov I. One-stage allotransplantation of thoracic segment of the trachea in a patient with idiopathic fibrosing mediastinitis and marked tracheal stenosis. Eur J Cardiothorac Surg 1993;7:383-6. DOI PubMed

39. Rose K, Sesterhenn K, Wustrow F. Tracheal allotransplantation in man. Lancet 1979;313:433. DOI PubMed

40. Delaere P, Vranckx J, Verleden G, De Leyn P, Van Raemdonck D; Leuven Tracheal Transplant Group. Tracheal allotransplantation after withdrawal of immunosuppressive therapy. N Engl J Med 2010;362:138-45. DOI PubMed

41. Xu L, Zhang S, Li J, et al. Human tracheal allotransplant with greater omentum for revascularization. Exp Clin Transplant 2014;12:448-53. PubMed

42. Lancet. The final verdict on Paolo Macchiarini: guilty of misconduct. Lancet 2018;392:2. DOI

43. Cyranoski D. Surgeon commits misconduct: papers authored by Paolo Macchiarini misrepresented success of pioneering tracheal transplant procedure. Nature 2015;521:406-8. DOI

44. Langer R, Tirrell DA. Designing materials for biology and medicine. Nature 2004;428:487-92. DOI PubMed

45. Langer R, Vacanti JP. Tissue engineering. Science 1993;260:920-6. DOI PubMed

46. Law JX, Liau LL, Aminuddin BS, Ruszymah BH. Tissue-engineered trachea: a review. Int J Pediatr Otorhinolaryngol 2016;91:55-63. DOI PubMed

47. Butler CR, Hynds RE, Gowers KH, et al. Rapid expansion of human epithelial stem cells suitable for airway tissue engineering. Am J Respir Crit Care Med 2016;194:156-68. DOI PubMed PMC

48. Nomoto M, Nomoto Y, Tada Y, et al. Bioengineered trachea using autologous chondrocytes for regeneration of tracheal cartilage in a rabbit model. Laryngoscope 2013;123:2195-201. DOI PubMed

49. Hamilton NJI, Lee DDH, Gowers KHC, et al. Bioengineered airway epithelial grafts with mucociliary function based on collagen IVand laminin-containing extracellular matrix scaffolds. Eur Respir J 2020;55:1901200. DOI PubMed PMC

50. Conconi MT, De Coppi P, Di Liddo R, et al. Tracheal matrices, obtained by a detergent-enzymatic method, support in vitro the adhesion of chondrocytes and tracheal epithelial cells. Transpl Int 2005;18:727-34. DOI PubMed

51. Zhao L, Sundaram S, Le AV, et al. Engineered tissue-stent biocomposites as tracheal replacements. Tissue Eng Part A 2016;22:108697. DOI PubMed PMC

52. Bhora FY, Lewis EE, Rehmani SS, et al. Circumferential three-dimensional-printed tracheal grafts: research model feasibility and early results. Ann Thorac Surg 2017;104:958-63. DOI PubMed

53. Rehmani SS, Al-Ayoubi AM, Ayub A, et al. Three-dimensional-printed bioengineered tracheal grafts: preclinical results and potential for human use. Ann Thorac Surg 2017;104:998-1004. DOI PubMed

54. Al-Ayoubi AM, Rehmani SS, Sinclair CF, Lebovics RS, Bhora FY. Reconstruction of anterior tracheal defects using a bioengineered graft in a porcine model. Ann Thorac Surg 2017;103:381-9. DOI PubMed

55. Gilbert TW, Freund JM, Badylak SF. Quantification of DNA in biologic scaffold materials. J Surg Res 2009;152:135-9. DOI PubMed PMC

56. Morris AH, Chang J, Kyriakides TR. Inadequate processing of decellularized dermal matrix reduces cell viability in vitro and increases apoptosis and acute inflammation in vivo. Biores Open Access 2016;5:177-87. DOI PubMed PMC

57. Cramer MC, Badylak SF. Extracellular matrix-based biomaterials and their influence upon cell behavior. Ann Biomed Eng 2020;48:2132-53. DOI PubMed PMC 
58. Grimmer JF, Gunnlaugsson CB, Alsberg E, et al. Tracheal reconstruction using tissue-engineered cartilage. Arch Otolaryngol Head Neck Surg 2004;130:1191-6. DOI PubMed

59. Lee CJ, Moon KD, Choi H, Woo J, Min BH, et al. Tissue engineered tracheal prosthesis with acceleratedly cultured homologous chondrocytes as an alternative of tracheal reconstruction. J Cardiovasc Surg (Torino) 2002;43:275-9. PubMed

60. Kang JY, Chung CW, Sung JH, et al. Novel porous matrix of hyaluronic acid for the three-dimensional culture of chondrocytes. Int $J$ Pharm 2009;369:114-20. DOI PubMed

61. Weidenbecher M, Tucker HM, Gilpin DA, Dennis JE. Tissue-engineered trachea for airway reconstruction. Laryngoscope 2009;119:2118-23. DOI PubMed PMC

62. Dikina AD, Strobel HA, Lai BP, Rolle MW, Alsberg E. Engineered cartilaginous tubes for tracheal tissue replacement via selfassembly and fusion of human mesenchymal stem cell constructs. Biomaterials 2015;52:452-62. DOI PubMed PMC

63. Komura M, Komura H, Kanamori Y, et al. An animal model study for tissue-engineered trachea fabricated from a biodegradable scaffold using chondrocytes to augment repair of tracheal stenosis. J Pediatr Surg 2008;43:2141-6. DOI PubMed

64. Hamaji M, Kojima F, Koyasu S, et al. Development of a composite and vascularized tracheal scaffold in the omentum for in situ tissue engineering: a canine model. Interact Cardiovasc Thorac Surg 2014;19:357-62. DOI PubMed

65. Gao B, Jing H, Gao M, et al. Long-segmental tracheal reconstruction in rabbits with pedicled Tissue-engineered trachea based on a 3D-printed scaffold. Acta Biomater 2019;97:177-86. DOI PubMed

66. Luo X, Liu Y, Zhang Z, et al. Long-term functional reconstruction of segmental tracheal defect by pedicled tissue-engineered trachea in rabbits. Biomaterials 2013;34:3336-44. DOI PubMed

67. Gao M, Zhang H, Dong W, et al. Tissue-engineered trachea from a 3D-printed scaffold enhances whole-segment tracheal repair. Sci Rep 2017;7:5246. DOI PubMed PMC

68. Kojima K, Bonassar LJ, Roy AK, Vacanti CA, Cortiella J. Autologous tissue-engineered trachea with sheep nasal chondrocytes. $J$ Thorac Cardiovasc Surg 2002;123:1177-84. DOI PubMed 